\title{
Eficiência da mensuração de progesterona salivar para identificar a ovulação em cadelas
}

\author{
Efficiency of salivary progesterone measurement to identify the ovulation in bitches
}

\author{
Patricia Rotta LOPES ${ }^{1}$; Priscila Viau FURTADO ${ }^{1}$; Claudio Alvarenga de OLIVEIRA ${ }^{1}$ \\ ${ }^{1}$ Departamento de Reprodução Animal da Faculdade de Medicina Veterinária e Zootecnia da Universidade de São Paulo, \\ São Paulo-SP, Brasil
}

\begin{abstract}
Resumo
Vários autores enfatizaram a importância do monitoramento do ciclo estral em cadelas e citaram exemplos de como realizar tal procedimento. O objetivo deste estudo foiavaliar a técnica de dosagem de progesterona salivarem cadelas para identificar a ovulação nesta espécie. Para composição do grupo experimental, foram utilizadas 13 cadelas, de diferentes raças (sem raça definida, Buldogue Inglês, Bernesse Mountain Dog) e diferentes idades (11 meses a 9 anos). Amostras de sangue e saliva foram colhidas simultaneamente em todos os animais, a partir dos primeiros sinais clínicos de proestro. Amostras salivares foram obtidas com o uso de dispositivo comercial específico (Salivette ${ }^{\circledR}$ ). Este método foi eficaz, visto ter tornado possível obter volume suficiente para dosagem de progesterona na grande maioria das amostras (100 $\mu \mathrm{L}$ para dosagens em duplicata). As concentrações de progesterona no soro foram determinadas pela técnica de radioimunoensaio e na saliva por enzimaimunoensaio, ambas com kits comerciais. Observou-se uma relação linear crescente e positiva entre a progesterona sérica e salivar $(\mathrm{r}=0,704 ; \mathrm{p}<0,0001)$ em cadelas. Uma das cadelas apresentou ciclo anovulatório, no qual, durante 13 dias, as concentrações séricas de progesterona sérica se mantiveram entre 1,67 e $3,76 \mathrm{ng} / \mathrm{mL}$ e as concentrações salivares de progesterona entre 19,55 e 236,77 pg/mL. Conclui-se que as concentrações de progesterona salivarmensuradas pela técnica de enzimaimunoensaio podem ser utilizadas para avaliar a ocorrência ou ausểncia de ovulação em cadelas.
\end{abstract}

Palavras-chave: Imunoensaio. Progesterona. Saliva. Cadelas. Reprodução.

\begin{abstract}
Several authors have emphasized the importance of monitoring estrous cycle in bitches and mentioned technique examples of how it can be done. The aim of this study was to evaluate the salivary progesterone quantification technique in order to identify ovulation in this species. To compound the experimental group, 13 bitches of different breeds (no specific breed, English Bulldog, Bernesse Mountain Dog)and different ages (from 11 months to 9 years old) were used. Blood and saliva samples were collected simultaneously in all animals, starting about the first day of proestrus clinical signs. Salivary samples were collected with a specific commercial device (Salivette ${ }^{\circledast}$ ). This method was effective, since it has become possible to obtain enough volume in almost all samples to quantify salivary progesterone $(100 \mu \mathrm{L}$ for duplicate quantification). Serum progesterone was quantified by radioimmunoassay and salivary progesterone by enzyme immunoassay, both of them with commercial kits. There was an increasing, linear and positive correlation between salivary and serum progesterone $(r=0.704 ; \mathrm{p}<0.0001)$ in bitches. One of the animals had an anovulatory cycle, in which, for 13 days, seric progesterone levels were maintained between 1.67 and $3.76 \mathrm{ng} / \mathrm{mL}$ and salivary progesterone levels were maintained between 19.55 and $236.77 \mathrm{pg} / \mathrm{mL}$. It was concluded that salivary progesterone levels measured by enzyme immunoassay is a technique that can be used to evaluate the presence or absence of ovulation in bitches.
\end{abstract}

Keywords: Immunoassay. Progesterone. Saliva. Bitches. Reproduction.

\section{Introdução}

O interesse na espécie canina e o conhecimento de suas particularidades reprodutivas aumentaram atualmente, pois, além de serem animais de companhia, são utilizados como modelos experimentais para outras espécies de canídeos ${ }^{1}$.

Vários autores já enfatizaram a importância do monitoramento do ciclo estral em cadelas e citaram mé- todos utilizados para tal procedimento ${ }^{2,3,4,5}$. A forma mais prática e usual para o monitoramento refere-se a observação do comportamento sexual do animal,

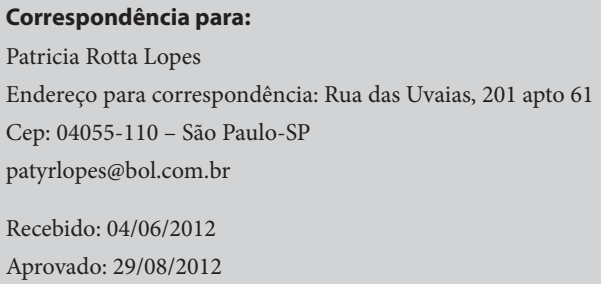


como edema vulvar, secreção vaginal sanguinolenta, atraçãoe aceitação do macho, associada à citologia vaginal. No entanto, algumas cadelas não manifestam comportamento sexual normal e podem, por exemplo, não aceitarmachos para o acasalamento. Nesses casos, o comportamento sexual não pode ser utilizado como parâmetro, ficando a citologia vaginal como método isolado, que é adequada para predizer a fase do ciclo estral da cadela, mas nem sempre eficaz quando utilizada isoladamente ${ }^{2,5}$.

Determinar o momento da ovulação na cadela não é simples e por isso é altamente recomendável a utilização de exames clínicos complementares ${ }^{6}$. Vários métodos são descritos para este fim, sendo os principais a mensuração das concentrações séricas de LH (hormônio luteinizante) e de progesterona e a vaginoscopia ${ }^{4}$ A vaginoscopia não permite determinar com acurácia o dia da ovulação ${ }^{6}$.A dosagem de LH nas cadelas, embora seja a alternativa ideal, rotineiramente não é empregada, pois não há ensaios comerciais disponíveis na maioria dos países. Tais circunstâncias levam muitos pesquisadores e clínicos a optarem pela mensuração das concentrações de progesterona sérica para determinar a ocorrência da ovulação ${ }^{1,6}$.

A relação entre as concentrações plasmáticas de progesterona e a evolução da fase folicular na cadela pode ser considerada a seguinte: $<1 \mathrm{ng} / \mathrm{mL}$ no anestro ou proestro; 1,0 a $1,9 \mathrm{ng} / \mathrm{mL}$ no dia anterior ao pico de LH; 2,0 a 2,9 ng/mL no dia do pico de LH; 3,0 a $3,9 \mathrm{ng} / \mathrm{mL}$ no dia anterior a ovulação; 4,0 a 10,0 ng/ $\mathrm{mL}$ no dia da ovulação; $>10 \mathrm{ng} / \mathrm{mL}$ após a ovulação. A ovulação ocorre cerca de 50 horas após o pico de $\mathrm{LH}^{7}$.

A partir dos conhecimentos sobre a distribuição dos esteroides pela corrente sanguínea, seu metabolismo e vias de excreção, vários trabalhos vêm sendo realizados sobre a fisiologia reprodutiva de animais utilizando diferentes matrizes biológicas ${ }^{8}$. A dosagem da progesterona em fluidos biológicos é um indicador útil e preciso, sendo utilizada para controlar a atividade ovariana em diferentes espécies animais ${ }^{9}$. Amostras de saliva, um fluido biológico de fácil obtenção,têm sido utilizadas na mensuração de esteroides reprodutivos femininos em diferentes espécies ${ }^{10,11,12}$.

No presente estudo objetivou-se verificar a eficiência da mensuração das concentrações de progesterona na saliva, uma matriz biológica alternativa ao soro, como um método para identificar a ovulação em cadelas, baseando-se na hipótese de que há correlação positiva entre as concentrações séricas e salivares de progesterona. Para tanto, tornaram-se objetivos específicos: mensurar as concentrações séricas e salivares de progesterona nas fases de proestro, estro e diestro e verificar se há correlação entre as concentrações séricas e salivares de progesterona em cadelas.

\section{Material e Método}

Foram utilizadas 13 cadelas de diferentes idades (11 meses a 9 anos) e raças, sendo seis $(46,2 \%)$ da raça Buldogue Inglês (cadelas C1 a C6), duas (15,4\%) da raça Bernesse Mountain Dog (C7 e C8) e cinco $(38,5 \%)$ sem raça definida (SRD) (C9 a C13), todas hígidas e não castradas. Em duas das 13 cadelas foram colhidasamostras em dois cios sequenciais, totalizando 15 momentos periovulatórios. As amostras de sangue e saliva foram colhidas paralelamente em todos os animais, a partir dos primeiros sinais de proestro, que foram obrigatoriamente o aparecimento de edema vulvar e descarga vaginal sanguinolenta. A quantidade de amostras por animal foi de 1 a 15 , com média de seis amostras por animal, totalizando 83 amostras de sangue e 83 amostras de saliva. $\mathrm{O}$ intervalo entre as colheitas sequenciaisem cada animal variou de 1 a 7 dias, com média de 2 dias de intervalo entre as coletas.

As coletas de sangue foram realizadas através da punção de veia jugular, cefálica ou safena, após antissepsia, com seringas descartáveis de $5 \mathrm{~mL}$ e agulhas hipodérmicas 25x8mm, utilizando-se tubos com gel separador. 
Os tubos foram centrifugados a $1500 \mathrm{~g}$ por 15 minutos e o soro obtido foi acondicionado em microtubos de $1,5 \mathrm{~mL}$ de polietileno.As amostras salivares foram obtidas com o uso de dispositivo de poliéster específico para colheita de saliva (Salivette ${ }^{\circledast}$, Sarstedt, Alemanha). O swab de poliéster do dispositivo foi inserido na boca dos animais por cerca de dois minutos e introduzido no tubo plástico do dispositivo, que então foi centrifugado a $1500 \mathrm{~g}$ por 15 minutos. A saliva resultante era acondicionada em microtubos de 1,5 $\mathrm{mL}$ de polietileno. Todas as amostras foram devidamente identificadas e armazenadas em freezer a $-20^{\circ} \mathrm{C}$ até a etapa subsequente de dosagem hormonal.

As concentrações de progesterona das amostras séricas foram determinadas no Laboratório de Dosagens Hormonais (LDH), do Departamento de Reprodução Animal da Faculdade de Medicina Veterinária e Zootecniada Universidade de São Paulo. As concentrações de progesterona no soro foram determinadas pela técnica de RIE (radioimunoensaio) em fase sólida, utilizando-se o conjunto diagnósticocomercial desenvolvido para dosagem hormonal de progesterona em soro humano (Coat-A-Count ${ }^{\oplus}$, Siemens, Los Angeles-CA, USA), já validado para dosagem de progesterona sérica na espécie canina ${ }^{13}$. Todas as etapas laboratoriais foram realizadas de acordo com as metodologias propostas pelos fabricantes.As amostras foram dosadas em duplicata.Todos os parâmetros de controle de qualidade dos ensaios hormonais foram analisados conforme rotina empregada no $\mathrm{LDH}^{8,11,14}$. Foram realizados dois ensaios. Os coeficientes de variação intraensaio baixo foram $8,42 \%$ e $9,70 \%$, os coeficientes de variação intraensaio alto foram $2,49 \% \mathrm{e}$ $3,87 \%$ e os coeficientes de variação interensaio baixo e alto foram respectivamente $8,42 \%$ e $2,48 \%$. A sensibilidade mínima detectada foi de $0,003 \mathrm{ng} / \mathrm{mL}$ e 0,004 $\mathrm{ng} / \mathrm{mL}$. A capacidade de ligação destes ensaios foi de $55 \%$ e $48 \%$.As concentrações de progesterona sérica foram expressas em $\mathrm{ng} / \mathrm{mL}$.
As concentrações de progesterona das amostras salivares foram determinadas no $\mathrm{LDH}$, do Departamento de Reprodução Animal da FMVZ/USP. As amostras de saliva passaram por dois ciclos de congelamento e descongelamento e posterior centrifugação a $2500 \mathrm{~g}$ por 10 minutos para remoção de resíduos. A progesterona salivar foi dosada pela técnica de EIE (enzimaimunoensaio), utilizando o conjunto diagnóstico comercial Salimetrics ${ }^{\oplus}$ (StateCollege, PA, USA), desenvolvido para dosagem hormonal de progesterona em saliva humana. Todas as etapas laboratoriais foram realizadas de acordo com as metodologias propostas pelos fabricantes. As amostras foram dosadas em duplicata. Foi realizado apenas um ensaio. O controle de qualidade do ensaio foi realizado através da análise dos coeficientes de variação intraensaio baixo e alto, que foram $6,33 \% \mathrm{e}$ 2,55\%, respectivamente; sensibilidade mínima detectada, que foi de 5,042 pg/mL; e capacidade de ligação que foi de $92 \%$. As concentrações de progesterona salivar foram expressas em $\mathrm{pg} / \mathrm{mL}$.

As análises estatísticas e os gráficos foram realizados utilizando os programas SPSS 19.0 (@ SPSS, Inc.); Statview 5.1. (@ SAS, Inc.) e Excel (๔ Microsoft). Os dados foram testados quanto à normalidade pelo teste de Shapiro-Wilk.

O teste de correlação de Pearson foi utilizado para verificar a relação entre as variáveis paramétricas, ou seja, entre as dosagens sérica e salivar de progesterona. Para esta análise, foi utilizado $n=76$. Os resultados foram expressos através do coeficiente de correlação (r), adotando-se um nível de significância de 5\%. Para descrição dos resultados, foram empregadas as médias e seus respectivos erros padrão dos dados originais. As médias foram comparadas utilizando-se análise de variância para medidas repetidas.

\section{Resultados}

Não foi possível obter volume de saliva suficiente para dosagem de progesterona em sete $(8,4 \%)$ amos- 
tras. O conjunto diagnóstico utilizado para quantificação requer o volume de $50 \mu \mathrm{L}$ de saliva para dosagem de progesterona, ou seja, $100 \mu \mathrm{L}$ de saliva para dosagem em duplicata. Então, entre as 83 amostras obtidas, sete possuíam volume inferior a $100 \mu \mathrm{L}$, restando 76 amostras para o estudo. A média de volumes de saliva obtidos nestas amostras foi de $220,3 \mu \mathrm{L}$.

Observou-se uma relação linear crescente e positiva entre as dosagens sérica e salivar de progesterona com coeficiente de correlação $r=0,704$ ( $p<0,0001)$ (Figura 1).

Para os períodos periovulatórios, para que todos os animais fossem alinhados temporalmente, determinou-se D0 como o dia inicial da ocorrência da ovulação. O início da ovulação (D0) em cada período foi considerado o dia em que foi obtido o primeiro valor acima de $4 \mathrm{ng} / \mathrm{mL}$ na concentração de progesterona sérica. Quando este valor não foi de fato obtido, o D0 foi estimado levando-se em consideração os valores das concentrações de progesteronaobtidos anterior e posteriormente.

Os perfis da progesterona sérica e salivar foram obtidos através das médias das concentrações des- te hormônio, em cada uma das matrizes biológicas, nos animais C1, C2, C3, C4, C5, C8, C9, C10, C12, totalizando noveanimais. Nos animais C3 e C10 foram analisados dois cios subsequentes, totalizando 11 períodos periovulatórios. Nos outros animais não foi possível determinar o início da ovulação (D0). As amostras obtidas de C6, C11 e C13 foram insuficientes. Em C7, os níveis de progesterona não se elevaram durante os 15 dias consecutivos de colheita.

A figura 2 e a tabela 1 apresentam as médias e seus respectivos erros padrão dos resultados obtidos referentes às concentrações séricas e salivares de progesterona dos nove animais em 11 períodos periovulatórios. Os valores médios de progesterona sérica elevaram-se a partir de D2 $(\mathrm{p}<0,05)$. Os valores médios de progesterona salivar elevaram-se em D5, mas declinaram em D6, voltando a elevarem-se em D9 $(p<0,05)$.

\section{Discussão}

O método utilizado neste estudo para obtenção de saliva em cadelas, o uso do dispositivo específico para coleta Salivette, mostrou-se eficaz, visto que foi pos-

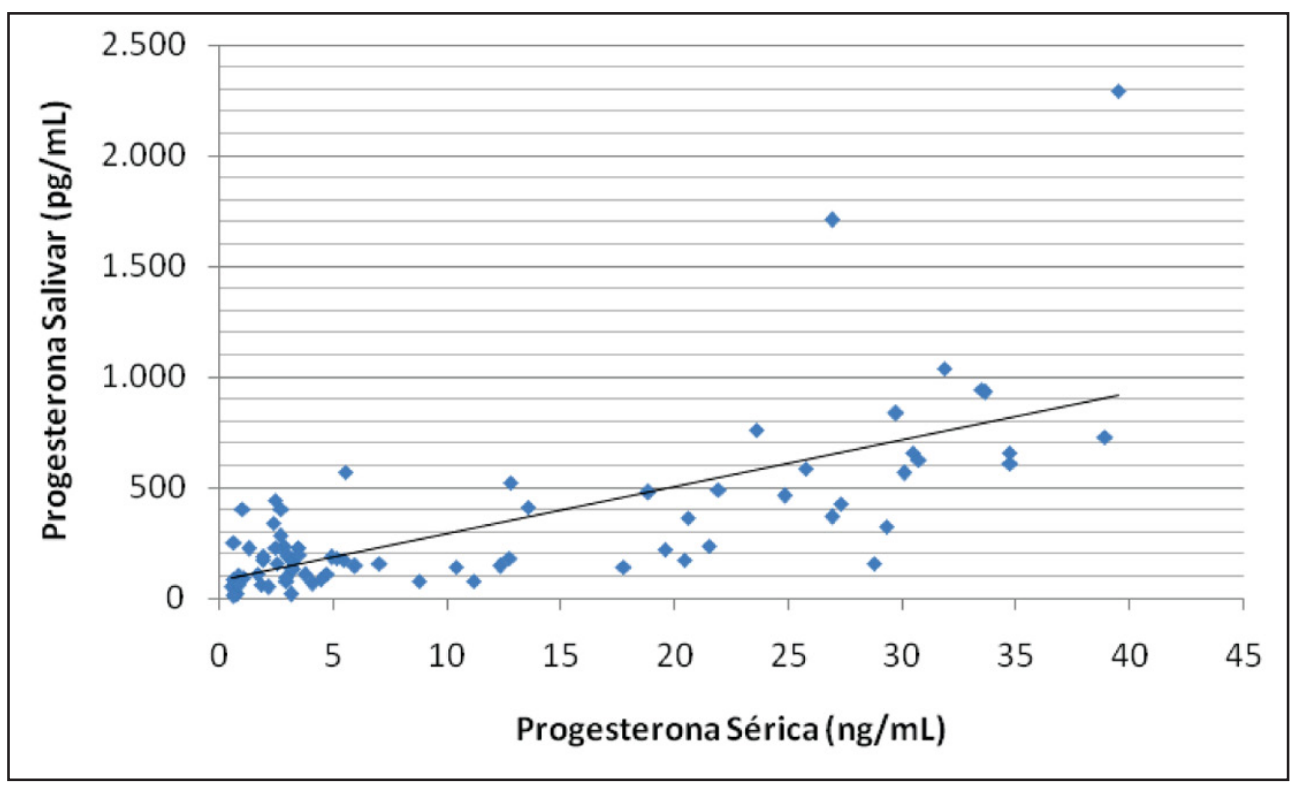

Figura 1 - Representação gráfica da regressão linear, mostrando relação crescente e positiva entre as concentrações séricas e salivares de progesterona em cadelas no período periovulatório 


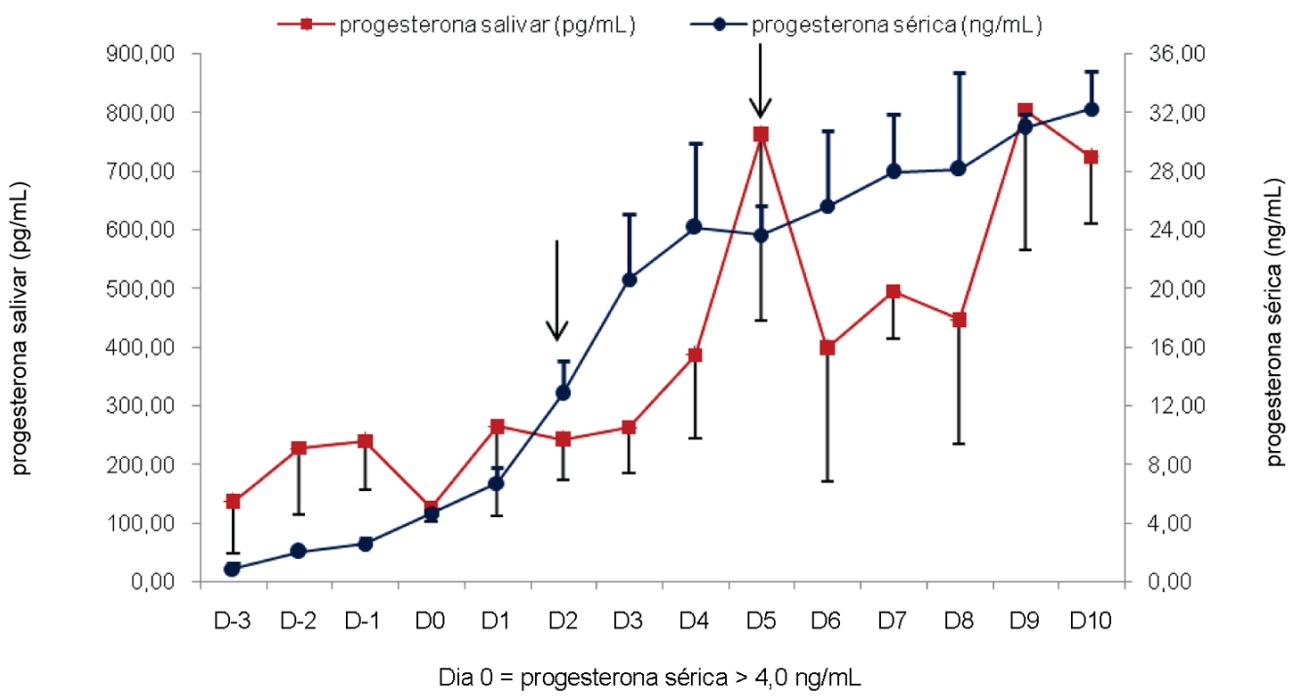

Figura 2 - Concentrações médias e erro padrão de progesterona sérica e salivar em nove cadelas e 11 períodos periovulatórios, considerando D0 o dia em que foi obtido o primeiro valor acima de $4 \mathrm{ng} / \mathrm{mL}$ na concentração sérica de progesterona. As setas indicam os momentos em que aconteceram os primeiros aumentos significativos nas concentrações de progesterona sérica (primeira seta, da esquerda para a direita) e salivar (segunda seta, da esquerda para a direita)

Tabela1 - Concentrações médias e erro padrão de progesterona sérica e salivar em nove cadelas e 11 períodos periovulatórios, considerando D0 o dia em que foi obtido o primeiro valor acima de $4 \mathrm{ng} /$ $\mathrm{mL}$ na concentração sérica de progesterona

\begin{tabular}{ccc}
\hline Dias & $\begin{array}{c}\text { média progesterona sérica } \\
(\mathrm{ng} / \mathrm{mL})\end{array}$ & $\begin{array}{c}\text { média progesterona salivar } \\
(\mathrm{pg} / \mathrm{mL})\end{array}$ \\
\hline D-3 & $0,89 \pm 0,39^{\mathrm{a}}$ & $136,71 \pm 87,55^{\mathrm{a}}$ \\
D-2 & $2,05 \pm 0,19^{\mathrm{a}}$ & $227,89 \pm 113,07^{\mathrm{a}}$ \\
D-1 & $2,59 \pm 0,38^{\mathrm{a}}$ & $240,15 \pm 83,58^{\mathrm{a}}$ \\
D0 & $4,66 \pm 0,19^{\mathrm{a}}$ & $125,58 \pm 23,92^{\mathrm{a}}$ \\
D1 & $6,73 \pm 1,03^{\mathrm{a}}$ & $264,89 \pm 153,66^{\mathrm{a}}$ \\
D2 & $12,83 \pm 2,27^{\mathrm{b}}$ & $242,94 \pm 68,61^{\mathrm{a}}$ \\
D3 & $20,63 \pm 4,42^{\mathrm{b}}$ & $262,68 \pm 76,45^{\mathrm{a}}$ \\
D4 & $24,17 \pm 5,73^{\mathrm{b}}$ & $386,58 \pm 141,42^{\mathrm{a}}$ \\
D5 & $23,64 \pm 1,98^{\mathrm{b}}$ & $762,40 \pm 316,82^{\mathrm{b}}$ \\
D6 & $25,60 \pm 5,17^{\mathrm{b}}$ & $398,86 \pm 226,85^{\mathrm{a}}$ \\
D7 & $27,91 \pm 3,93^{\mathrm{b}}$ & $494,63 \pm 79,94^{\mathrm{a}}$ \\
D8 & $28,11 \pm 6,60^{\mathrm{b}}$ & $446,78 \pm 210,64^{\mathrm{a}}$ \\
D9 & $30,97 \pm 0,88^{\mathrm{b}}$ & $803,82 \pm 237,70^{\mathrm{b}}$ \\
D10 & $32,25 \pm 2,52^{\mathrm{b}}$ & $723,95 \pm 113,08^{\mathrm{b}}$ \\
\hline
\end{tabular}

Letras distintas nas colunas indicam diferenças significativas entre as concentrações de progesterona para cada matriz biológica $(\mathrm{p}<0,05)$

sível obter volume suficiente para dosagem de progesterona na grande maioria das amostras (91,6\%). Entre os dispositivos comerciais para coleta de saliva, apenas o Salivette ${ }^{\circledast}$ de poliéster é adequado para aná- lise de esteroides salivares, pois o uso de materiais de algodão para coleta interfere nos resultados de imunoensaios. Os resultados são artificialmente altos nas dosagens de progesterona quando o algodão é utilizado para absorver saliva durante a coleta ${ }^{15}$.

Como já relatado em outras espécies ${ }^{11,12,16,17}$, a correlação entre progesterona sérica e salivar na cadela é também positiva, confirmando a hipótese.

O perfil hormonal de progesterona sérica mostrou crescentes concentrações do hormônio ao longo do tempo em relação à primeira coleta, com aumento significativo a partir de D2, momento em que a progesterona atinge concentrações séricas de 12,83 ng/ $\mathrm{mL}$. Estes resultados contrariam, em parte, os obtidos por outros autores, que observaram concentrações de progesterona crescentes significativas $(p<0,001)$ de 0,8 a $2,6 \mathrm{ng} / \mathrm{mL}$ em um intervalo de dois dias ${ }^{18}$. Um estudo feito por outro autor obteve diferença estatística significativa nas concentrações de progesterona entre o dia anterior e o primeiro dia de receptividade sexual, mas não na transição entre o final do estro e começo do diestro ${ }^{19}$. Outro trabalho encontrou au- 
mento significativo nas concentrações de progesterona no dia do pico de $\mathrm{LH}^{20}$. As diferenças dos resultados obtidos entre este trabalho e os supracitados devem-se às diferenças metodológicas neles empregadas e às elevadas variações interindividuais. No trabalho primeiramente supracitado, por exemplo, foram utilizadas 20 cadelas e as coletas sanguíneas ocorreram diariamente, o que possibilitou uma maior amostra estatística ${ }^{16}$.

O perfil hormonal de progesterona salivar obtido neste estudo mostrou aumento significativo na concentração deste hormônio em D5, porém não foi mantido, voltando a apresentar aumento significativo a partir de D9. Os resultados nas concentrações salivares de progesterona apresentaram aumento significativo dois dias após os obtidos nas concentrações séricas e uma inconsistência em relação ao parâmetro sérico, fato este que contraria o esperado. Embora haja dados na literatura que demonstram não haver influência do fluxo salivar nas concentrações de esteroides salivares em humanos e nem da higiene dental na estabilidade deste hormônio ${ }^{12,21,22}$, não há estas informações para cães. No presente estudo, não foi medida a taxa de flu- xo salivar e nem tampouco realizados exames para avaliar higiene e saúde buco-dental dos animais. Quando se realiza dosagem de esteroides em amostras urinárias, os valores individuais de creatinina são utilizados na correção dos valores obtidos para impedir que as variações de volume possam influir nos valores de hormônios mensurados, pois a creatinina não sofre alteração mesmo que os volumes urinários sejam diferentes ${ }^{11}$. Não há nenhum parâmetro semelhante para corrigir variações no volume salivar.

Houve uma cadela (C7) que, após manifestar sinais de proestro, não apresentou aumento nas concentrações de progesterona sérica e salivar ao longo do tempo. As concentrações séricas de progesterona se mantiveram entre 1,67 e 3,76 $\mathrm{ng} / \mathrm{mL}$ e as de progesterona salivar entre 19,55 e 236,77 pg/mL (Figura 3). Embora de difícil ocorrência, a cadela apresentou um ciclo anovulatório. Nestes casos, as concentrações séricas de progesterona não se elevam mais do que 3,5 a $6,0 \mathrm{ng} / \mathrm{mL}$, devido às elevadas concentrações de estradiol, o que não permite a ocorrência do pico de $\mathrm{LH}^{6}$. Este evento pode acontecer nos casos de cistos foliculares ou devido a um proestro muito prolongado. Em

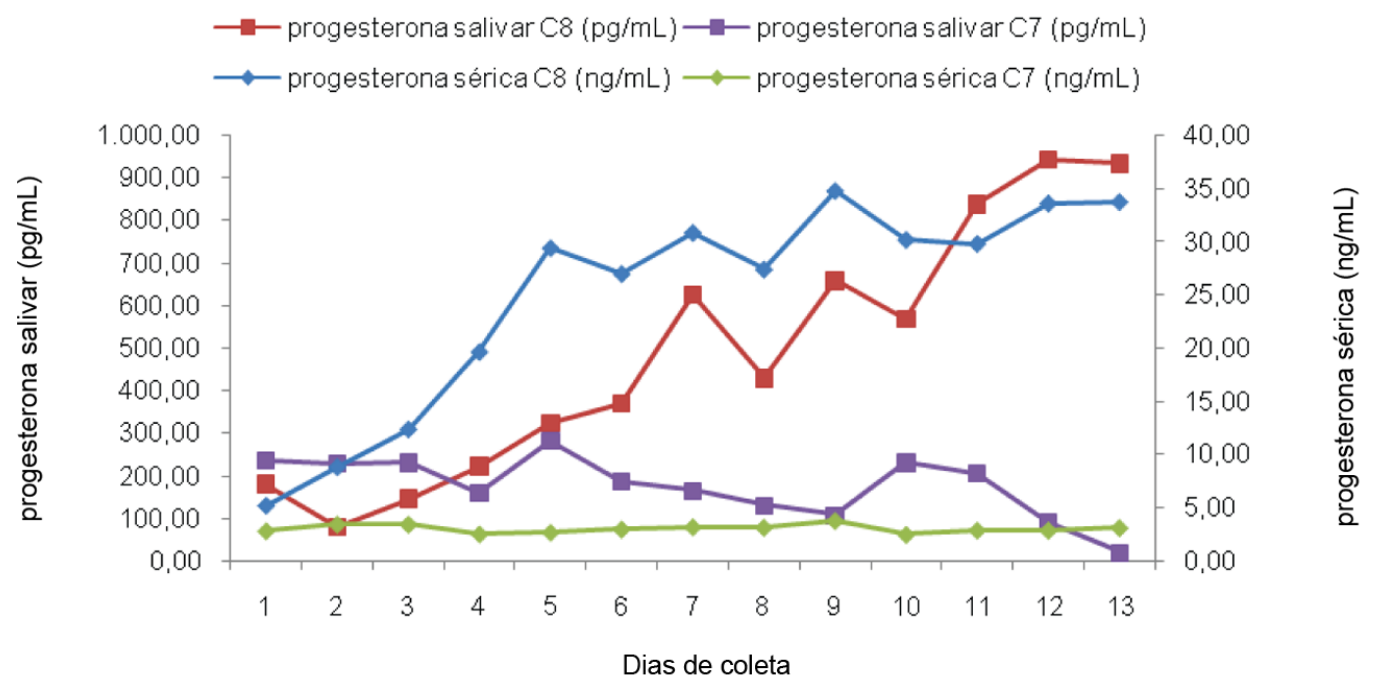

Figura3 - Concentrações séricas e salivares de progesterona em duas cadelas da raça Bernesse Mountain Dog durante 13 dias consecutivos, caracterizando um momento periovulatório atípico (C7) e um típico (C8) 
algumas fêmeas, o primeiro proestro não evolui para estro e pode terminar em três ou mais semanas. Nesses casos, não há maturação folicular devido a uma insuficiente estimulação hipofisária. Segundo o autor, fêmeas com proestro e estro normal raramente apresentam falhas de ovulação ${ }^{23}$.

Autores avaliaram a concentração de progesterona em amostras salivares colhidas diariamente de mulheres durante todo o ciclo menstrual e encontraram que o perfil de progesterona na saliva refletiu o classicamente encontrado em sangue ${ }^{24}$. Um autor, porém, ao investigar métodos não invasivos para monitorar a função ovariana cíclica da mulher, não obteve sucesso ao tentar usar o primeiro aumento significante na concentração salivar de progesterona como método para predizer ovulação. Este aumento, no entanto, marcou o final do período fértil em mais de $80 \%$ das pacientes. Os resultados obtidos neste trabalho se assemelham aos encontrados por este autor, pois, embora não tenhamos conseguido usar o primeiro aumento significante na concentração salivar de progesterona para predizer a ovulação, pode-se usar esse dado para predizer que o período fértil da cadela se encerrou, embora haja variações individuais ${ }^{10}$.

\section{Referências}

1.DERUSSI, A. A. P.; LOPES, M. D. Fisiologia da ovulação, da fertilização e do desenvolvimento embrionário inicial na cadela. Revista Brasileira de Reprodução Animal, v. 33, n. 4, p. 231-237, 2009

2.SILVA, L. D. M.; SILVA, A. R.; CARDOSO, R. C. S. Inseminação artificial em cães. In: GONÇALVES, P. B. D.; FIGUEIREDO, J. R.; FREITAS, V. J. F. Biotécnicas aplicadas à reprodução animal. São Paulo: Varela, 2001. p. 69-95.

3. LUZ, M. R. Manejo del apareamiento em la especie canina. In: GOBELLO, C. (Org.). Temas de reproducción de caninos y felinos por autores latino-americanos. La Plata: Intermédica, 2004. p. 99-106.

4.SCHAEFERS-OKKENS, A. C. Ciclo Estral e Manejo Reprodutivo da Cadela Sadia. In: ETTINGER, S. J.; FELDMAN, E. C. Tratado de medicina interna veterinária: doenças do cão e do gato. 4. ed. Rio de Janeiro: Guanabara Koogan, 2004. v. 2, p. 1592-1602.

5. OLIVEIRA, E. C. S.; MARQUES JR., A. P. Endocrinologia reprodutiva e controle da fertilidade da cadela. Revista Brasileira de Reprodução Animal, v. 30, n. 1/2, p. 11-18, 2006.
O RIE utiliza material radioativo, o que requer licenças especiais junto aos órgãos reguladores. Com o desenvolvimento de programas de responsabilidade ambiental, foram desenvolvidas alternativas a esse método radioativo para a quantificação hormonal em soro humano, como o EIE, a quimiluminescência e a espectrometria de massas. As enzimas são os marcadores mais utilizados na atualidade, com as vantagens de não apresentarem riscos associados à exposição de radioisótopos. O EIE apresenta ainda outras vantagens sobre o RIE: maior sensibilidade; menos trabalho e economia de tempo; uso mais econômico do anticorpo e utilização de equipamentos de menor custo ${ }^{14}$.

\section{Conclusão}

Nas condições em que o experimento foi conduzido, pode-se concluir que é possível utilizar a mensuração de progesterona salivar para identificar ovulação em cadelas, visto que há correlação entre as concentrações de progesterona na matriz sérica e salivar.

\section{Agradecimentos}

À Agência FAPESP, pelo financiamento do projeto.

6. FANTBONNE, A. Infertility in bitches and queens: recent advances. Revista Brasileira de Reprodução Animal, v. 35, n. 2, p. 202-209, 2011.

7.ALVES, I.; MATEUS, M.; LOPES DA COSTA, L. Monitorização do ciclo éstrico da cadela para inseminação artificial ou cruzamento. In: CONGRESSO DE CIÊNCIAS VETERINÁRIAS, 1., 2002, Lisboa. Proceedings of the veterinary sciences congress. Lisboa: Sociedade Portuguesa de Ciências Veterinárias, 2002. p. 177-182.

8. AMARAL, R. S. Uso de diferentes matrizes biológicas na dosagem de andrógenos em peixes-bois da Amazônia machos (Trichechus inunguis) mantidos em cativeiro. 2008. 85 f. Dissertação (Mestrado em Medicina Veterinária) Faculdade de Medicina Veterinária e Zootecnia, Universidade de São Paulo, São Paulo, 2008.

9. CARREIRA, R. P.; COLAÇO, A. A.; SILVA, J. R. Avaliação da estabilidade da progesterona em diferentes tipos de amostras: soro e leite desnatado. Revista Portuguesa de Ciências Veterinárias, v. 98, n. 548, p. 207-209, 2003.

10.CAMARGOS, A. F. Investigação de métodos não invasivos 
para monitorar a função ovariana na mulher. Reprodução, v. 4, p. 25-34, 1989.

11.FURTADO, P. V. Perfil analítico de estrógenos e progestinas em diferentes matrizes biológicas na espécie ovina (Ovis aires). 2007. 96 f. Tese (Doutorado em Medicina Veterinária) Faculdade de Medicina Veterinária e Zootecnia, Universidade de São Paulo. São Paulo, 2007.

12.PIRES, A. L. Estudo do perfil salivar e sérico em gestantes e não-gestantes. 2008. 87 f. Dissertação (Mestrado em Ciências da Saúde) - Universidade de Brasília, Brasília, 2008.

13.SRIKANDAKUMAR, A.; INGRAHAM, R. H.; ELLSWORTH, M.; ARCHBALD., L. F.; LIAO A.; GODKE, R. A. Comparison of a solid-phase, no-extraction radioimmunoassay for progesterone with an extraction assay for monitoring luteal function in the mare, bitch, and cow. Theriogenology, v. 26, n. 6, p. $779-793,1986$

14. RODINI, D. C. Perfil analítico das progestinas fecais nas fases de puberdade e ciclicidade ovariana em Onça Pintada (Panthera onca); gestação e lactação em Gato Mourisco (Puma yagouaroundi). 2008. 74 f. Tese (Doutorado em Medicina Veterinária) - Faculdade de Medicina Veterinária e Zootecnia, Universidade de São Paulo, São Paulo, 2008.

15. GRÖSCHL. M.; RAUH, M. Influence of commercial collection devices for saliva on the reliability of salivary steroids analysis. Steroids, v. 71, n. 13-14, p. 1097-1100, 2006.

16.GAO, Y.; SHORT, R. V.; FLETCHER, T. P. Progesterone concentrations in plasma, saliva and milk of cows in different reproductive states. British Veterinary Journal, v. 144, n. 3, p. 262-268, 1988.

17.PIETRASZEK, J.; ATKINSON, S. Concentrations of estrone sulfate and progesterone in plasma and saliva, vaginal cytology, and bioelectric impedance during the estrous cycle of the Hawaiian monk seal (Monachus schauinslandi).Marine Mammal Science, v. 10, n. 4, p. 430-441, 1994.

18.CONCANNON, P. W.; HANSEL, W.; VISEK, W. J. The ovarian cycle of the bitch: plasma estrogen, LH and progesterone. Biology of Reproduction, v.13, n. 1, p. 112-121, 1975.

19.ROTA, A.; VERONESI, M. C.; VOLPE，S.; RICCARDI, A.; BATTOCCHIO, M. Estradiol-17 $\beta$, progesterone and testosterone plasma concentrations during estrus in the bitch. Veterinary Research Communications, v. 31, n.1, p. 197-199, 2007.

20.WILDT, D. E.; PANKO, W. B.; CHAKRABORTY, P. K.; SEAGER, S. W. J. Relationship of serum estrone, estradiol-17 $\beta$ and progesterone to $\mathrm{LH}$, sexual behavior and time of ovulation in the bitch. Biology of Reproduction, v. 20, n. 3, p. 648-658, 1979.

21.VINING, R. F.; MCGINLEY, R. A.; SYMONS, R. G. Hormones in Saliva: Mode of Entry and Consequent Implications for Clinical Interpretation. Clinical Chemistry, v. 29, n. 10, p. 1752-1756, 1983.

22.BOEVER, J. D.; KOHEN, F.; BOUVE, J.; LEYSEELE D.; VANDEKERCKHOVE, D. Direct chemiluminescence immunoassay of estradiol in saliva. Clinical Chemistry, v. 36, n. 12, p. 2036-2041, 1990.

23. ALLEN, W. E. Fertilidade e obstetrícia no cão. São Paulo: Varela, 1995. 197 p.

24.CAMARGOS, A. F.; DONALDSON, A.; SUFI, S. B.; JEFFCOATE, A. L. Qual o valor dos constituintes da saliva para predizer ovulação? Reprodução, v. 3, n. 1, p. 25-28, 1988. 